\title{
Doença meningocócica: situação epidemiológica atual no Brasil
}

\section{Meningococcal disease: current epidemiological situation in Brazil}

Joanna Calmeto Guedes ${ }^{1}$, Igor Pereira de Carvalho ${ }^{1}$, Juliana Jangelavicin Barbosa ${ }^{1}$, Luiza de Aguiar Missel ${ }^{1}$, Lara Thauana Guimarães Pena ${ }^{1}$, Luciano Rodrigues Costa $^{1}$ e Clarisse Pereira Dias Drumond Fortes ${ }^{1}$

'Escola de Ciências Médicas de Volta Redonda

\section{Palavras-chave:}

Meningite meningocócica; Epidemiologia; Relatos de casos; Óbito.

\section{Resumo}

Introdução: a doença meningocócica é patologia de notificação compulsória, causada pela bactéria Neisseria meningitidis, capaz de produzir amplo espectro clínico, cujos fatores de risco estão relacionados a aglomeração no domicílio, tabagismo, dentre outros. No Brasil, é uma doença endêmica com ocorrência periódica de surtos epidêmicos em vários municípios e principal causadora de meningite bacteriana. Como medidas de prevenção e controle são realizadas a vacinação e a quimioprofilaxia. Objetivo: o trabalho tem como objetivo principal a análise crítica sobre os casos confirmados e óbitos ocorridos por doença meningocócica registrados entre os anos de 2010 e 2017. Métodos: realizou-se um estudo descritivo dos casos confirmados e dos óbitos por doença meningocócica registrados no Sistema de Informação de Agravos de Notificação, com data do início dos sintomas em janeiro de 2010 a dezembro de 2016. A data da atualização do banco de dados do sistema foi abril de 2017. Resultados: quando comparados os casos confirmados no ano de 2010 e 2016, percebe-se um declínio. Quando se analisa o número de óbitos, verifica-se que este diminuiu mais de 60\%. A taxa de incidência também decaiu significativamente. Apesar da queda observada, a taxa de letalidade vem mantendo-se estável. Conclusões: de acordo com nossa interpretação dos dados analisados, os casos confirmados, assim como os óbitos por doença meningocócica, diminuíram ao longo dos anos, principalmente depois da introdução da vacina meningocócica conjugada para o sorogrupo C. Apesar de todo sucesso observado, é necessário manter uma vigilância efetiva sobre a doença meningocócica.

\section{Keywords:}

Meningitis, meningococcal; Epidemiology; Case reports; Death.

\begin{abstract}
Introduction: meningococcal disease is a condition of compulsory notification, caused by the bacterium Neisseria meningitidis, capable of producing a broad clinical spectrum. Its risk factors are related to agglomeration at home, smoking, among others. In Brazil, it is an endemic disease with periodic outbreaks of epidemics in several municipalities and the main cause of bacterial meningitis. Vaccination and chemoprophylaxis are performed as prevention and control measures. Objective: the main objective of this study is to analyze the confirmed cases and deaths due to meningococcal disease between the years 2010 and 2017. Methods: a descriptive study of the confirmed cases and deaths by meningococcal disease registered in the Sistema de Informação de Agravos de Notificação [Notifiable Diseases Information System], with symptoms starting in January/2010 to December/2016. The update of the database was in April 2017. Results: when comparing the confirmed cases in the years of 2010 and 2016, one perceives a decline. When the number of deaths is analyzed, it is found a decrease by more than $60 \%$. The incidence rate also declined significantly. Despite the decline observed above, the lethality rate has remained stable. Conclusions: our interpretation of the data analyzed was that the confirmed cases, as well as the deaths due to meningococcal disease, decreased over the years, mainly after the introduction of the meningococcal conjugate vaccine for serogroup C. Despite all the success observed it is necessary to maintain an effective surveillance of meningococcal disease.
\end{abstract}




\section{INTRODUÇÃO}

A doença meningocócica é uma patologia imprevisível e grave, causada pela bactéria Neisseria meningitidis, que é capaz de produzir um amplo espectro clínico, que, por sua vez, pode variar desde portador assintomático até meningococcemia fulminante. ${ }^{1}$ A meningite é a principal manifestação e está presente em aproximadamente $70 \%$ dos casos sintomáticos. Essa apresentação é resultante da disseminação hematogênica da bactéria e se assemelha a outras formas de meningite purulenta. Já a meningococcemia se apresenta com início súbito de febre, calafrios, mal-estar, mialgia, dor em membros, prostração e um exantema petequial, que pode progredir para púrpura fulminante e costuma atingir de 4 a $20 \%$ dos casos. ${ }^{2,3}$

A Neisseria meningitidis é um diplococo Gram-negativo, aeróbio, imóvel, que costuma colonizar o trato respiratório superior dos seres humanos e sua transmissão ocorre por meio das secreções respiratórias. ${ }^{1}$ Ela é dividida em 12 diferentes sorogrupos segundo a composição antigênica da cápsula polissacarídica, sendo os sorogrupos A, B, C, Y, W e X os principais responsáveis pela ocorrência da doença invasiva. Além da divisão em sorogrupos, a bactéria também é classificada em sorotipos e sorossubtipos, de acordo com a composição antigênica das proteínas de membrana externa PorB e PorA, respectivamente. ${ }^{4}$

Os fatores de risco para desenvolver a doença incluem: infecções respiratórias virais recentes, aglomeração no domicílio, residir em quartéis, dormir em acampamento militar ou em alojamentos de estudantes, tabagismo, condições socioeconômicas menos favorecidas e contato íntimo com portadores da bactéria. É importante frisar que o risco de adoecimento entre contatos domiciliares de um doente é superior 500 vezes do que na população geral. ${ }^{1,4}$

A doença meningocócica representa um importante problema de saúde pública em todo o mundo devido às suas elevadas taxas de incidência e mortalidade, ${ }^{1}$ embora não seja possível estimar precisamente esses números, devido à vigilância inadequada em diversas partes do mundo. Além dessas elevadas taxas de letalidade, a doença meningocócica causa grande morbidade, com 12 a $20 \%$ dos sobreviventes com sequelas tais como: surdez, deficiência mental, amputações. ${ }^{5}$

No Brasil, é uma doença endêmica com ocorrência periódica de surtos epidêmicos em vários municípios e a principal causa de meningite bacteriana no país, sendo o sorogrupo C o mais frequente desde 2005. ${ }^{4}$ Por esse motivo, é uma patologia de notificação compulsória, sendo os surtos, os aglomerados de casos e os óbitos de notificação imediata. ${ }^{4,6}$

Como medida de prevenção e de controle da doença são realizadas a vacinação e a quimioprofilaxia com antibióticos. A primeira é a forma mais eficaz de prevenção, e consiste na administração das vacinas sorogrupos e

Figura 1 - Casos confirmados e óbitos por doença meningocócica no Brasil (2010-2016)

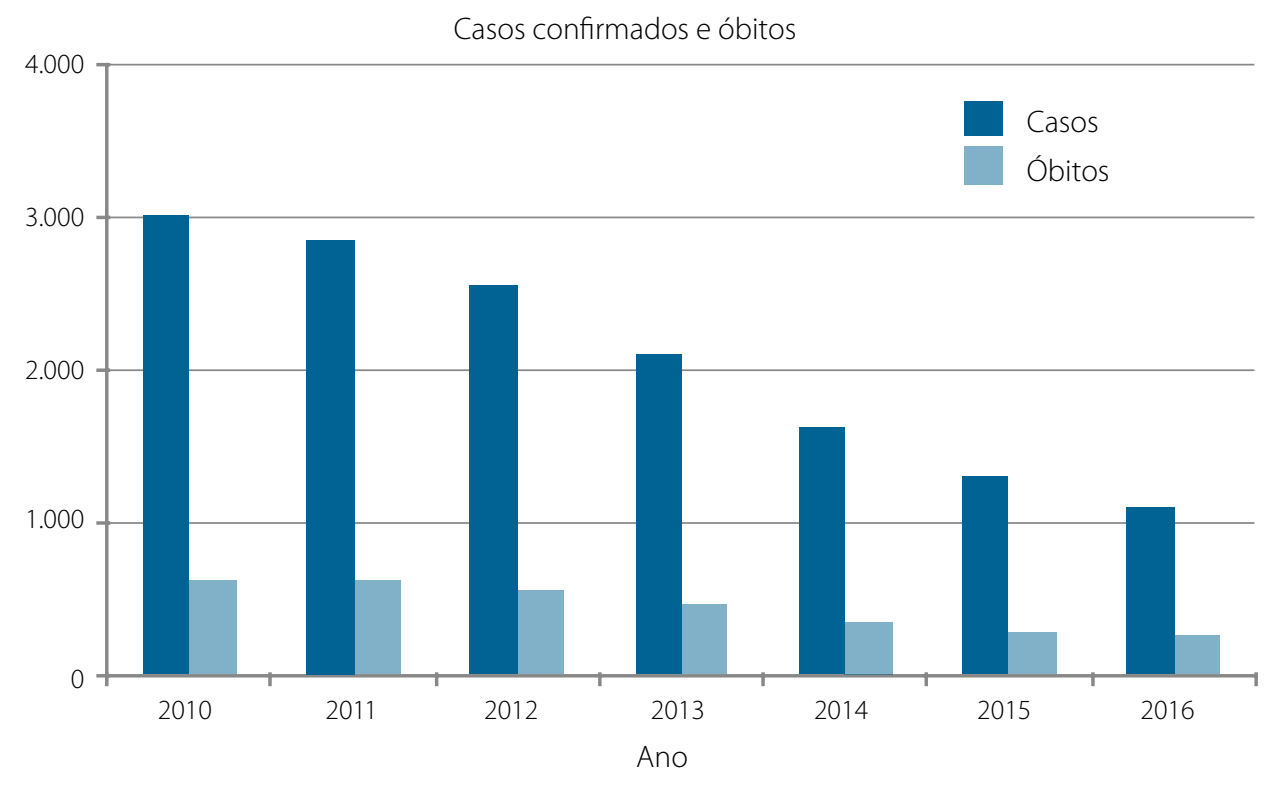

Fonte: Adaptado de Sinan/SVS/CGDT/UVRI (2017). 
sorossubtipos específicas, embora nenhuma das vacinas tenha eficácia de $100 \%$ na imunização. ${ }^{1}$ Já a segunda, embora não assegure um efeito protetor absoluto e prolongado, tem sido adotada como medida eficaz na prevenção de casos secundários e é recomendada para os contatos próximos de casos suspeitos, assim como para o paciente no momento da alta ou na internação, além dos profissionais de saúde que realizaram procedimentos invasivos sem utilização de equipamento de proteção individual. ${ }^{4}$

O presente trabalho tem como objetivo principal a análise crítica sobre os casos confirmados e óbitos ocorridos por doença meningocócica registrados entre os anos de 2010 e 2017.

\section{MÉTODO}

Foi realizado um estudo descritivo dos casos confirmados e dos óbitos de doença meningocócica registrados no Sistema de Informação de Agravos de Notificação (Sinan), com data do início dos sintomas de janeiro de 2010 a dezembro de 2016. A data da atualização do banco de dados do sistema foi abril de 2017.

\section{RESULTADOS}

No Brasil, durante o período de 2010 a 2017, foram registrados 14.532 casos confirmados de doença meningocócica e 3.082 óbitos. Ao se comparar os casos confirmados no ano de 2010 e 2016, percebe-se uma queda de $63,20 \%$. Já quando se analisa o número de óbitos, verifica-se que este diminuiu mais de $60 \%$. Na figura 1 é possível observar que o número de casos e óbitos vem sendo reduzido ao longo do período estudado.

Ao longo desses anos foi possível verificar, conforme a figura 2, que houve uma queda significativa na taxa de incidência de tal patologia, chegando ao número de menos de 1 caso a cada 100 mil habitantes.

Figura 2 - Incidência da doença meningocócica (2010-2016)

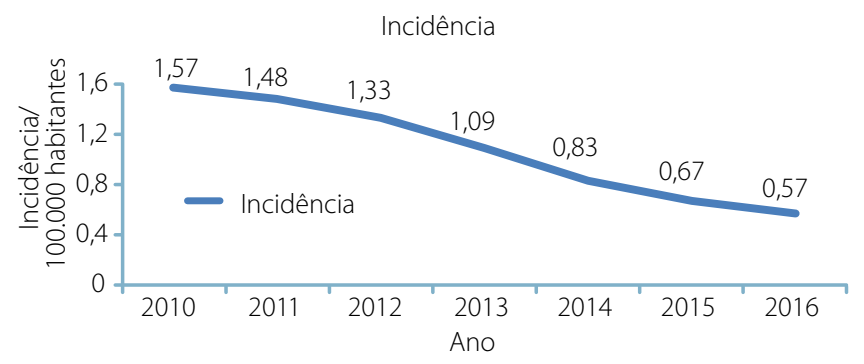

Fonte: Adaptado de Sinan/SVS/CGDT/UVRI (2017).?

Apesar da redução do número de óbitos por doença meningocócica, a taxa de letalidade se mantém estável ao longo dos anos, sendo a menor obtida em 2010, com $20,5 \%$ e a maior taxa em 2016, como 21,9\% (Figura 3).

Figura 3 - Taxa de letalidade por doença meningocócica no Brasil

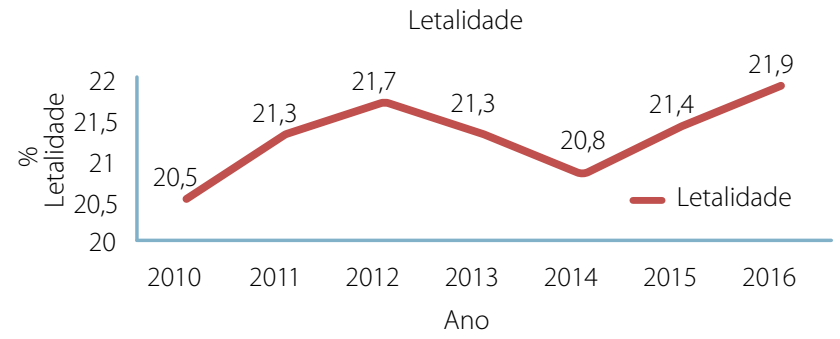

Fonte: Adaptado de Sinan/SVS/CGDT/UVRI (2017).

\section{DISCUSSÃO}

No Brasil, o sorogrupo C continua a ser a causa mais comum da doença meningocócica. Os outros sorogrupos não tiveram um aumento significativo, como ocorreu em outros países da América Latina. ${ }^{5}$

Durante o período de 2007 a 2013, foram registrados os sorogrupos A, B, C, E, W e Y, sendo mais frequentes o B e o C. Para o sorogrupo B, a taxa de incidência foi reduzida entre 2007 (0,15 casos/100 mil habitantes) e 2010 (0,10 casos/100 mil habitantes). Em relação aos outros sorogrupos, a incidência aumentou de 0,03 casos por 100 mil habitantes, em 2007, para 0,05 casos a cada 100 mil habitantes em 2008, permanecendo estável até $2013 .^{8}$

Acredita-se que a queda observada no número de casos confirmados e óbitos, assim como na taxa de incidência esteja relacionada à imunização infantil com a vacina conjugada MenC, adicionada ao Programa Nacional de Imunizações do Ministério da Saúde em 2010. O cronograma da imunização preconiza a vacinação de lactentes aos 3 e 5 meses, com uma dose de reforço aos 12 meses, além de uma dose única para crianças entre 12 e 23 meses, e adolescentes com 12 a 14 anos incompletos. ${ }^{4,5}$

As vacinas meningocócicas atualmente utilizadas no Brasil são as formas MenA, MenC, MenACWY e MenCY-Hib. A vacina meningocócica quadrivalente ACWY pode ser conjugada ao toxoide tetânico (ACWYTT) e é licenciada a partir de 12 meses de idade; já a vacina meningocócica ACWY, conjugada ao mutante diftérico (ACWY-CRM), a partir de 2 anos de idade. As duas vacinas recombinantes proteicas contra o sorogrupo B foram recentemente licenciadas em diferentes países da Europa, no Canadá, EUA e Austrália, com segurança e eficácia. Uma delas, com a tecnologia denominada Bexsero ${ }^{\circledR}$, foi licenciada no Brasil para uso a partir dos 2 meses até os 50 anos de idade. ${ }^{9}$ 
Segundo Jafri ${ }^{10}$ o Brasil ainda apresenta uma incidência moderada, embora já se observe os efeitos positivos da introdução da vacinação na população a partir de 2010. Deus ${ }^{11}$ avalia que vacinação MenC, realizada no Estado da Bahia, teve um impacto positivo sobre a taxa de incidência da doença meningocócica. A autora afirma ainda que a taxa de efetividade da vacina foi superior a $92 \%$, o que ultrapassa o resultado obtido no Reino Unido.

\section{CONCLUSÕES}

Em nossa interpretação dos dados, os casos confirmados, assim como os óbitos por doença meningocócica, diminuíram ao longo dos anos, principalmente depois da introdução da vacina meningocócica conjugada para o sorogrupo C. Apesar desses avanços nos números, há necessidade de observação contínua diante do surgimento de novos surtos.

É importante frisar que a vacinação proporciona uma proteção significativa para a população, assim como é um componente significativo do controle de doença meningocócica, com evidência observada na queda da taxa de incidência de tal doença no país.

Apesar de todo sucesso visto, é imperativo manter uma vigilância efetiva da doença meningocócica. Recomenda-se ainda a realização de outros estudos sobre as taxas de incidência e mortalidade, assim como sobre o impacto da vacina ao longo dos próximos anos.

\section{AGRADECIMENTOS}

Agradecemos ao Centro Universitário de Volta Redonda (UniFOA) o ambiente criativo e amigável que proporciona.

\section{REFERÊNCIAS}

1 Rabelo BL, Nobre M, Lima S, Vandesmet L. Aspectos microbiológicos e imunológicos da meningite bacteriana. Mostra Científica em Biomedicina (Centro Universitário Católica de Quixadá). 2016;1(1). Disponível em: http://publicacoesacademicas.fcrs.edu.br/index.php/ mostrabiomedicina/article/view/815/731

2 Motta F. Doença meningocócica: quadro clínico, diagnóstico e tratamento. Doença meningocócica - Fascículo 3. Sociedade Brasileira de Pediatria: Porto Alegre - RS; 2015. Disponível em: http://www.sbp.com.br/fileadmin/user_upload/publicacoes/ Folheto_Meningite_Fasciculo3_111115.pdf

3 Takada S, Fujiwara S, Inoue T, Kataoka Y, Hadano Y, Matsumoto K et al. Meningococcemia in adults: a review of the literature. Intern Med. 2016;55(6):567-72.

4 Brasil. Ministério da Saúde. Secretaria de Vigilância em Saúde. Coordenação-Geral de Desenvolvimento da Epidemiologia em Serviços. Guia de Vigilância em Saúde. [acesso em: 8 ago 2017]. v. l. Brasília: Ministério da Saúde; 2017. Disponível em: http://www.hc.ufu.br/sites/default/files/tmp//volume_1_ guia_de_vigilancia_em_saude_2017.pdf.

5 Borrow R, Alarcón P, Carlos J, Caugant DA, Christensen H, Debbag R et al. The Global Meningococcal Initiative: global epidemiology, the impact of vaccines on meningococcal disease and the importance of herd protection. Expert Rev Vaccines. 